\title{
Identification of the key amino acid residues in Sabellastarte arginine kinase for distinguishing chiral guanidino substrates (D- and L-arginine)
}

Kouji Uda*, Aiko Matumoto, Tomohiko Suzuki

Laboratory of Biochemistry, Faculty of Science, Kochi University, Kochi 780-8520 Japan,

*Corresponding author

e-mail: k-uda@cc.kochi-u.ac.jp

fax: $+81-88-844-8359$

Keywords D-amino acid - guanidino kinase - phosphagen kinase - arginine kinase creatine kinase - substrate specificity - Sabellastarte indica

Abbreviations used: AK, arginine kinase; CK, creatine kinase; GK, glycocyamine kinase; GS region, guanidine specificity region; LK, lombricine kinase; TK, taurocyamine kinase; TSAC, transition state analog complex. 


\begin{abstract}
Arginine kinase (AK, EC 2.7.3.3) is a phosphagen kinase widely distributed in lower and higher invertebrates. Sabellastarte indica AKs (AK1 and AK2) are the only AKs that use D-arginine in addition to L-arginine as a substrate. Sabellastarte indica AKs are therefore clearly unrelated to typical AK. The purpose of this work was to identify the amino acid residues responsible for distinguishing the chirality of $\mathrm{D}$ - and L-arginine. The three-dimensional structure of Sabellastarte AK2 was predicted using the SWISS-MODEL automated modeling server. Two amino acids, L64 in the N-terminal flexible loop and N320 in the C-terminal flexible loop, were found to be closest to the substrate arginine. We introduced several mutations around the predicted binding site of the substrate arginine. In the L64I mutant, the affinity for L-arginine was greatly increased (9.5-fold that of the wild-type), whereas its affinity for D-arginine was increased 2.9-fold, indicating that the L64I mutant enzyme was more specific for L-arginine. On the other hand, the L64V mutant showed a 1.7-fold decrease in affinity for L-arginine, but unchanged affinity for D-arginine. Thus the L64V mutant enzyme was more specific for D-arginine. Since the replacement of amino acid residue L64 by I or V significantly affected the affinity for L-arginine or D-arginine, it can be concluded that amino acid 64 is a key residue for distinguishing D- and L-arginine. Seven mutants at position 320 (N320H, Q, D, E, R, K and A) had considerably reduced enzymatic activity ( 0.05 to $52 \%$ of the wild-type). The reduction in enzyme activity was more significant when D-arginine was the substrate rather than L-arginine, except for N320D, suggesting that the carbonyl oxygen of the Asn320 side chain forms a hydrogen bond with the $\alpha$-amino nitrogen attached to the asymmetric carbon of the D-arginine substrate. In addition, we found that even a residue remote from the guanidino substrate binding site, such as G54 and Y89 in Sabellastarte
\end{abstract}


AK2, significantly affected guanidino substrate specificity. 


\section{Introduction}

Phosphagen (guanidino) kinases catalyze the reversible transfer of the high-energy phosphoryl group of ATP to naturally occurring guanidine compounds. Members of this enzyme family play a key role in animals as ATP buffering systems in cells that display high and variable rates of ATP turnover [1-3]. The phosphorylated high-energy guanidines are referred to as phosphagens. In vertebrates, phosphocreatine is the only phosphagen, and the corresponding phosphagen kinase is creatine kinase (CK). In contrast, invertebrates have various phosphagens in addition to phosphocreatine: phosphoglycocyamine (catalyzed by glycocyamine kinase: GK), phosphotaurocyamine (taurocyamine kinase: TK), phosphohypotaurocyamine (hypotaurocyamine kinase: HTK), phospholombricine (lombricine kinase: LK) and phosphoarginine (arginine kinase: AK). Phosphagen kinases are phylogenetically separated into two distinct groups: the AK group which includes AK and HTK, and the CK group which includes GK, LK and TK [4].

Typical AKs are most widely distributed among organisms such as arthropods, molluscs, nematodes, cnidarians, poriferae, protozoans (ciliates and choanoflagellates) and bacteria, indicating their ancient origin [5-8]. Most AKs are monomers with an average molecular mass of approximately $40 \mathrm{kDa}[2]$. Unusual dimeric $\mathrm{AKs}$ have been isolated from the deuterostome echinoderm, Stichopus japonicus [9, 10] and the protostome annelid, Sabellastarte indica [11], which evolved secondarily and independently from CK-like ancestors [12].

We recently reported that, although typical AKs and the unusual Stichopus AK display activity only for L-arginine, two AK isoforms (AK1 and AK2) isolated from Sabellastarte showed activity for both L-arginine and D-arginine. The activity for D-arginine was weak in $\mathrm{AK} 1$, but stronger in $\mathrm{AK} 2$ (50\% that of L-arginine). In addition, D-arginine and 
D-phosphoarginine were isolated directly from Sabellastarte at a high concentration (3-4 $\mathrm{mmol} / \mathrm{kg}$ ). From these results we concluded that, in Sabellastarte, D-arginine is the major phosphagen substrate and AK2 catalyzes the synthesis of D-phosphoarginine [11].

Previous amino acid sequence alignments of phosphagen kinases indicated that the guanidino specificity (GS) region can contain significant amino acid deletions, making it a likely candidate for the guanidine-recognition site [13]. For example, LK and AK have a five amino-acid deletion in this region and use relatively large guanidine substrates (lombricine and arginine), CK has a one-amino-acid deletion, and GK has no deletion. Additionally, the GS region is overlapped by the flexible loop in the N-terminal domain of Torpedo CK [14] and Limulus AK [15]. Unlike typical AKs, Sabellastarte AK1 and AK2 have three and two amino acid deletions in the GS region, respectively. This is in sharp contrast with the dimeric Stichopus AK, which evolved from a cytoplasmic CK gene [16], which has a five-amino-acid deletion, just like typical AKs. In addition, although the amino acid identity in the GS region for a specific enzyme is generally very high, Sabellastarte AK1 and AK2 show low similarity with other AKs [11].

In this work, we predicted the three-dimensional structure of Sabellastarte AK2 using SWISS-MODEL, and also estimated the positions of the guanidino substrates, chiral arginines. To identify the key residues responsible for distinguishing the chiral arginines, we introduced several mutations around the arginine binding site. Here we describe the importance of several amino acid residues: L64 and N320 (located closest to the substrate arginine), Y89 (the key residue for guanidino substrate recognition), and G54 (located at the beginning of the GS region).

\section{Materials and methods}




\subsection{Site directed mutagenesis and expression of Sabellastarte indica $A K 2$}

Sabellastarte indica was collected from the seashore of Tosa city, Kochi, Japan. The internal organs were removed immediately from living Sabellastarte indica, and the body wall musculature was frozen under liquid-nitrogen. The cDNA (open reading frame of 1134 base pairs, GenBank accession No. AB186406) of Sabellastarte indica AK2, amplified by PCR from first-strand cDNA derived from the body wall musculature and cloned into pMAL-c2, was used as template [11]. Polymerase chain reaction (PCR)-based mutagenesis was done as described previously [16]. The mutations (L64 to I, V, G and A, N320 to Q, D, E, R, K and A, Y89 to Q, and G54 to S, A, V, L and I) were introduced into the template by PCR using mutation-primers shown in sTable 1 (supplementary material). $\mathrm{KOD}^{+}$DNA polymerase (TOYOBO, Tokyo, Japan) was used as the amplifying in enzyme. The PCR products were digested with $D p n \mathrm{I}$, and the target DNA fragment (8000 bp) was recovered by EasyTrap Ver.2 (TaKaRa, Tokyo, Japan). After blunting and kination, the DNA was self-ligated. The cDNA insert was completely sequenced to confirm that only the intended mutations were introduced.

The MBP (maltose-binding protein)-Sabellastarte AK2 fusion protein was expressed in $\begin{array}{lllllll}\text { Escherichia coli cells by induction with } 0.5 & \mathrm{mM}\end{array}$ isopropyl-1-thio- $\beta$-D-galactopyranoside at $25{ }^{\circ} \mathrm{C}$ for $20 \mathrm{~h}$. The soluble protein was extracted with the Bugbuster (Novagen, WI, USA), and purified by affinity chromatography using amylose resin (New England BioLabs, MA, USA). Purity was checked by sodium dodecyl sulfate-polyacrylamide gel electrophoresis (SDS-PAGE). The enzymes were placed on ice until use, and enzymatic activity was determined within $12 \mathrm{~h}$.

\subsection{Enzyme assay and determination of kinetic constants}


Enzyme activity was measured with an NADH-linked assay at $25^{\circ} \mathrm{C}$ [17] and determined for the forward reaction (phosphagen synthesis). The reaction mixture (total $1.0 \mathrm{ml}$ ) for determination of $\mathrm{K}_{\mathrm{m}}{ }^{\mathrm{Arg}}$ contained $0.65 \mathrm{ml}$ of $100 \mathrm{mM}$ Tris/ $\mathrm{HCl}(\mathrm{pH} 8), 0.05 \mathrm{ml}$ of $750 \mathrm{mM}$ $\mathrm{KCl}, 0.05 \mathrm{ml}$ of $250 \mathrm{mM} \mathrm{Mg}$-Acetate, $0.05 \mathrm{ml}$ of $25 \mathrm{mM}$ phosphoenolpyruvate made up in $100 \mathrm{mM}$ imidazole/ $\mathrm{HCl}(\mathrm{pH} 7), 0.05 \mathrm{ml}$ of $5 \mathrm{mM}$ NADH made up in Tris/ $\mathrm{HCl}(\mathrm{pH} 8), 0.05$ $\mathrm{ml}$ of pyruvate kinase/lactate dehydrogenase mixture made up in $100 \mathrm{mM}$ imidazole/ $\mathrm{HCl}$ (pH 7), $0.05 \mathrm{ml}$ of $100 \mathrm{mM}$ ATP made up in $100 \mathrm{mM}$ imidazole/ $\mathrm{HCl}(\mathrm{pH}$ 7) and $0.05 \mathrm{ml}$ of recombinant enzyme. The reaction was started by adding $0.05 \mathrm{ml}$ of an appropriate concentration of L- or D-arginine made up in $100 \mathrm{mM}$ Tris/ $\mathrm{HCl}(\mathrm{pH}$ 8). The initial velocity values were obtained by varying the concentration of L- or D-arginine under the fixed concentrations of the ATP.

The reaction mixture (total $1.0 \mathrm{ml}$ ) for determination of $\mathrm{K}_{\mathrm{m}}{ }^{\text {ATP }}$ contained $0.7 \mathrm{ml}$ of 200 mM L- or D-arginine made up in $100 \mathrm{mM}$ Tris/HCl $(\mathrm{pH}$ 8), $0.05 \mathrm{ml}$ of $750 \mathrm{mM} \mathrm{KCl}, 0.05$ $\mathrm{ml}$ of $250 \mathrm{mM} \mathrm{Mg}$-Acetate, $0.05 \mathrm{ml}$ of $25 \mathrm{mM}$ phosphoenolpyruvate made up in $100 \mathrm{mM}$ imidazole $/ \mathrm{HCl}(\mathrm{pH} 7), 0.05 \mathrm{ml}$ of $5 \mathrm{mM} \mathrm{NADH}$ made up in Tris/ $\mathrm{HCl}(\mathrm{pH} 8), 0.05 \mathrm{ml}$ of pyruvate kinase/lactate dehydrogenase mixture made up in $100 \mathrm{mM}$ imidazole/ $\mathrm{HCl}(\mathrm{pH}$ 7), and $0.05 \mathrm{ml}$ of recombinant enzyme. The reaction was started by adding $0.05 \mathrm{ml}$ of an appropriate concentration of ATP made up in $\mathrm{mM}$ imidazole $/ \mathrm{HCl}(\mathrm{pH} 7)$.

Protein concentration was estimated from the absorbance at $280 \mathrm{~nm}$. The extinction coefficient at $280 \mathrm{~nm}$ in $\mathrm{M}^{-1} \mathrm{~cm}^{-1}$ (or $\mathrm{mg} / \mathrm{ml}$ ) was obtained using ProtParam (available from the URL http:/ca.expasy.org/tools/protparam.html). The extinction coefficient of the Y89Q mutant was calculated based on the mutated amino acid sequence. The protein concentration for the AK enzyme moiety was obtained by excluding the portion of the MBP tag. The kinetic parameters were determined by our previous method [18]. 


\subsection{Modeling of three-dimensional structures}

The three-dimensional structure of Sabellastarte AK2 was generated using the SWISS-MODEL automated modeling server (http://www.expasy.org/swissmod/ SWISS-MODEL.html; the First Approach Method set at default parameters). Swiss-PdbViewer version 4.0.1 was used to generate a three-dimensional image [19]. In order to predict the L-arginine binding site, the three-dimensional structure of Sabellastarte AK2 was superimposed on the transition-state analogue complex (TSAC) structure of Limulus AK (PDB number: 1BG0) [15]. The binding site for D-arginine was predicted by fitting it with L-arginine.

\section{Results and Discussion}

\section{Prediction of the three-dimensional structure of Sabellastarte $A K 2$}

The three-dimensional structure of Sabellastarte AK2 was generated by SWISS-MODEL based on the TSAC structures of Limulus AK and Torpedo CK, both of which have a similar substrate-binding site $[14,15]$. Then we estimated the position of the substrate arginine in Sabellastarte AK2 by overlapping the position of L-arginine in the TSAC structure of Limulus AK (Fig. 1). The predicted structure indicated that the L- or D-arginine substrate is close to L64 in the N-terminal flexible loop (GS region) and N320 on the C-terminal flexible loop. Y89, which is proposed to be the key residue for guanidino substrate recognition $[20,21]$, is also near the substrate arginines.

Expression of Sabellastarte AK2 wild-type and mutants, and their kinetic parameters Each recombinant enzyme was expressed as a soluble protein fused with maltose binding 
protein (MBP) and purified to a highly pure state by affinity chromatography. Of the 16 mutants constructed in this study, only five (L64I, L64V, Y89Q G54S and G54A) had sufficient activity to allow estimation of their kinetic parameters. The kinetic parameters ( $K_{\mathrm{m}}, k_{\mathrm{cat}}$ and $\left.k_{\mathrm{cat}} / K_{\mathrm{m}}\right)$ of the wild-type and five mutant enzymes in the presence of either Lor D-arginine were determined for the forward reaction, and are listed in Table 1 and 3. Seven other mutants at position 320 showed weak enzymatic activity, so only the initial velocities were measured in $4.76 \mathrm{mM}$ ATP and $4.76 \mathrm{mM}$ L- or D-Arginine (Table 2). The remaining five mutants (L64G, L64A, G54V, G54L and G54I) displayed undetectable enzymatic activity under the same conditions.

Phosphagen kinases usually show activity only for one guanidino substrate, whereas Sabellastarte AKs display activities for at least four guanidino substrates. Sabellastarte AK1 is primarily active towards L-arginine, but has weak but significant activity for D-arginine (7.6\% compared to L-arginine), D-lombricine (3.0\%) and taurocyamine $(2.7 \%)$. On the other hand, Sabellastarte AK2 shows strong activity towards both L-arginine (100\% relative activity) and D-arginine (35\% relative activity), but shows rather weak activities for D-lombricine $(0.2 \%)$ and taurocyamine $(0.1 \%)$ [22]. This large difference in substrate specificity is caused by the difference $(30 \%)$ in amino acid sequence of the GS region of Sabellastarte AK1 and AK2.

The wild type AK2 enzyme of Sabellastarte shows 2.4-fold higher substrate affinity for L-arginine $\left(K_{\mathrm{m}}^{\mathrm{L}-a r g}=3.69 \mathrm{mM}\right)$ than for D-arginine $\left(K_{\mathrm{m}}{ }^{\mathrm{D}-a r g}=9.00 \mathrm{mM}\right)$, but it has similar $k_{\text {cat }}$ values for L-arginine $\left(k_{\text {cat }}^{\mathrm{L}-\text { arg }}=46.0 \mathrm{~s}^{-1}\right)$ and D-arginine $\left(k_{\mathrm{cat}}^{\mathrm{D}-\mathrm{arg}}=40.8 \mathrm{~s}^{-1}\right)$, as shown in Table 1. It should be emphasized that there were no significant differences between $k_{\text {cat }}^{\text {L-arg }}$ and $k_{\text {cat }}^{\text {D-arg }}$ for all the mutant enzymes whose kinetic parameters were examined in this work, while the $K_{\mathrm{m}}^{\mathrm{D}-\mathrm{arg}} / K_{\mathrm{m}}^{\mathrm{L}-\text { arg }}$ ratio for the mutants changed remarkably, ranging 
from 1.3-8.1 (Table 1). This implies that the active center for the phosphoryl transfer mechanism is conserved in the L- and D-arginine substrates.

Five mutants (L64I, L64V, Y89Q G54S and G54A) showed comparable or higher catalytic efficiency for L-arginine $\left(k_{\text {cat }}^{\mathrm{L}-\arg } / K_{\mathrm{m}}^{\mathrm{L}-\arg }=9.65-195 \mathrm{~s}^{-1} \mathrm{mM}^{-1}\right)$ than the wild-type (12.5) (Table 1); the situation was the same for D-arginine $\left(k_{\mathrm{cat}}{ }^{\mathrm{D}-\arg } / K_{\mathrm{m}}{ }^{\mathrm{D}-\arg }=9.29-29.0\right.$ $\mathrm{s}^{-1} \mathrm{mM}^{-1}$ for the mutants, and 4.5 for the wild-type). These results clearly indicate that the native form of Sabellastarte AK2 suppresses the higher catalytic potential for both L-arginine and D-arginine as the wild type.

Key residues responsible for substrate recognition in Sabellastarte AK2

Amino acid 64

Amino acid residue 64 is located in the N-terminal flexible loop (GS region) and is closest to the substrate arginine in the predicted Sabellastarte AK2 structure (Fig. 1). The 64th residue is leucine in Sabellastarte AK2 but isoleucine in Sabellastarte AK1. The corresponding residues in LK, TK, GK, CK and Limulus $\mathrm{AK}$ are I, I, K, T and G, respectively.

We replaced L64 in Sabellastarte AK2 with G, A, I and V. The L64G and L64A recombinant enzymes were expressed as soluble proteins, but no enzymatic activity could be detected. In contrast, the L64I and L64V mutant enzymes showed high activity: 1.4- to 1.6-fold higher $k_{\text {cat }}$ for L-arginine than the wild-type enzyme, and 2.2-fold higher $k_{\text {cat }}$ for D-arginine (Table 1). These results indicate that an amino acid residue with a large hydrophobic side chain, such as $\mathrm{L}$, I or $\mathrm{V}$, is required at position 64 in order to suitably accommodate the substrate arginine and allow full expression of activity.

In the L64I mutant, the affinity for L-arginine $\left(K_{\mathrm{m}}^{\mathrm{L}-a r g}=0.389 \mathrm{mM}\right)$ was increased greatly 
(9.5-fold that of the wild-type), and $k_{\mathrm{cat}}^{\mathrm{L}-\text {-arg }} / K_{\mathrm{m}}^{\mathrm{L}-\text { arg }}$ was increased 15.6-fold (Table 1). The affinity for D-arginine $\left(K_{\mathrm{m}}^{\mathrm{D}-\text { arg }}=3.14 \mathrm{mM}\right)$ was increased 2.9 -fold (the $k_{\text {cat }}{ }^{\mathrm{D}-a r g} / K_{\mathrm{m}}{ }^{\mathrm{D}-a r g}$ increased 6.4-fold); although significant, these increases are smaller than for L-arginine. Comparison of the values of $\left(k_{\mathrm{cat}}^{\mathrm{D}-\mathrm{arg}} / K_{\mathrm{m}}^{\mathrm{D}-\mathrm{arg}}\right) /\left(k_{\mathrm{cat}}^{\mathrm{L}-\mathrm{arg}} / K_{\mathrm{m}}^{\mathrm{L}-\mathrm{arg}}\right)$, namely, 0.362 for wild-type and 0.149 for L64I (see Table 1 and Fig. 3), indicated that the L64I mutant had enhanced specificity for L-arginine. Finally, it should be noted that the high specificity for L-arginine of the Sabellastarte AK2 L64I mutant approaches that of Sabellastarte AK1 (wild-type), which has Ile at position 64.

On the other hand, the L64V mutant showed a 1.7-fold decrease in affinity for L-arginine $\left(K_{\mathrm{m}}^{\mathrm{L}-a r g}=6.45 \mathrm{mM}\right)$, but unchanged affinity for D-arginine $\left(K_{\mathrm{m}}{ }^{\mathrm{D}-\mathrm{arg}}=9.55 \mathrm{mM}\right)($ Table 1$)$. Thus the L64V mutation makes the enzyme more specific for D-arginine ( $\left(k_{\mathrm{cat}}{ }^{\mathrm{D}-a r g} / K_{\mathrm{m}}{ }^{\mathrm{D}-a r g}\right)$ $\left./\left(k_{\mathrm{cat}}^{\mathrm{L}-\arg } / K_{\mathrm{m}}^{\mathrm{L}-\arg }\right)=0.986\right)($ Fig. 3).

As shown above, since the replacement of L64 by I or V significantly affected affinity for L-arginine or D-arginine, it can be concluded that the 64th residue plays a critical role in distinguishing D- and L-arginine.

\section{$\underline{\text { Amino acid } 320}$}

As shown in Fig. 1, it was predicted that amino acid N320 in the C-terminal loop, as well as L64, is close to the substrate arginine in Sabellastarte AK2. Residue 320 is strictly conserved in $\mathrm{CK}$ as $\mathrm{D}$ and in typical AKs as $\mathrm{H}$. We constructed seven mutants differing at position $320(\mathrm{~N} 320 \mathrm{H}, \mathrm{Q}, \mathrm{D}, \mathrm{E}, \mathrm{R}, \mathrm{K}$ and A). All the mutants displayed weak enzymatic activity, so the exact kinetic parameters were not obtained. However, the initial velocities of these mutants were measured at the same substrate concentrations (Table 2). All the mutants showed a considerable reduction in enzymatic activity $(0.05$ to $52 \%$ of the 
wild-type), but the decrease was significantly larger with D-arginine than with L-arginine, except for the N320D mutant. In N320D, enzymatic activity towards L-arginine was decreased 3-fold and towards D-arginine 2-fold, making this the only enzyme with higher specificity for D-arginine among the seven mutants (see the value for D-Arg activity / L-Arg activity in Table 2 and Fig. 3). It is also noted that among the mutants, N320D maintain relatively high activity for both of L-arginine (32\%) and D-arginine (48 \%), and N320E only for D-arginine (48\%). These results suggest that the carbonyl oxygen of the N320 side chain is involved in recognizing the D-arginine substrate via a hydrogen bond with the $\alpha$-amino nitrogen attached to the asymmetric carbon of D-arginine. Thus, D320 and E320 could partly substitute for the role played by N320.

In the Torpedo CK TSAC structure, D320 forms a hydrogen bond with H66 on the N-terminal flexible loop and stabilizes the substrate-bound structure [14]. Moreover, in human muscle CK, it was reported that the disruption of the hydrogen bond (ion pair) between D320 and H66 caused a remarkable loss of activity ( $0.1 \%$ that of wild-type activity) [23]. If N320 in Sabellastarte AK2 is also hydrogen-bonded with a given residue on the N-terminal loop, as in CK, the remarkable loss of activity in the N320 mutants might be attributed partly to destabilization of the catalytic pocket formed by the N-terminal and C-terminal flexible loops.

\section{$\underline{\text { Amino acid } 89}$}

Amino acid residue- 89 is proposed to be one of the key residues for recognition of guanidino substrates in phosphagen kinases [20, 21]. Multiple alignments of amino acid sequences clearly indicated that the residue is strictly conserved as a specific amino acid in each phosphagen kinase: $\mathrm{R}$ in $\mathrm{CK}, \mathrm{Y}$ in typical $\mathrm{AK}, \mathrm{I}$ in GK, $\mathrm{H}$ in TK, and $\mathrm{K}$ in LK [24] 
(see Fig. 2). While this residue does not appear to be directly involved in substrate binding in the TSAC structures of $\mathrm{CK}$ and $\mathrm{AK}$, it is located close to the guanidine substrate-binding site $[14,15]$. Site-directed mutagenesis studies of this residue using rabbit CK and Einenia LK have shown that it has a significant effect on enzymatic activity and guanidino substrate specificity [20,21]. A recent report investigating Danio CK and Nautilus AK also showed that the 89th residue plays a key role in organizing the hydrogen-bond network between the four dynamic domains [25] of AK and CK, thereby helping provide an appropriate active center for high catalytic turnover [26].

We replaced Y89 in Sabellastarte AK2 with Q, the amino acid at this position in AK1 (see Fig. 2). The catalytic constants of the Y89Q mutant were increased 1.7-fold for L-arginine $\left(k_{\text {cat }}^{\text {L-arg }}=77.8 \mathrm{~s}^{-1}\right)$ and 1.5-fold for D-arginine $\left(k_{\text {cat }}^{\text {D-arg }}=61.5 \mathrm{~s}^{-1}\right)$, compared with those of the wild-type (46 and $40.8 \mathrm{~s}^{-1}$, respectively, see Table 1). On the other hand, the affinity for L-arginine was decreased 1.4-fold $\left(K_{\mathrm{m}}{ }^{\mathrm{L}-\mathrm{arg}}=5.07 \mathrm{mM}\right)$ compared with that of the wild-type (3.69 mM), but that for D-arginine was increased 1.4-fold $\left(K_{\mathrm{m}}^{\mathrm{D}-\mathrm{arg}}=6.45\right.$ mM). Clearly, Y89Q has more specificity for D-arginine. These results are consistent with the idea that the 89th amino acid is the key residue for guanidino substrate recognition [20, 21].

\section{$\underline{\text { Amino acid } 54}$}

Numerous mutations of the GS region of Sabellastarte AK2 highlighted the importance of G54, located at the beginning of the N-terminal loop (Fig. 1). This residue is conserved in typical AK, CK and GK, but is replaced by S, S and A in LK, TK and Sabellastarte AK1, respectively (Fig. 2). The G54V, G54L and G54I mutations yielded inactive enzymes, suggesting that the large hydrophobic side chains of V, L and I caused an unfavorable 
configuration of the N-terminal loop. In contrast, the G54S and G54A mutants showed 1.8and 2.6-fold increases in $k_{\text {cat }}$ for L-arginine, and 2.1- and 3.0-fold increases in $k_{\text {cat }}$ for D-arginine compared with those of wild-type (Table 1). The G54A mutant showed higher affinities for both L-arginine (1.4-fold that of the wild-type) and D-arginine (2.0-fold). In the G54S mutant, the affinity for L-arginine was increased 1.8-fold, but the affinity for D-arginine was unchanged. Comparison of the values of $\left(k_{\text {cat }}^{\mathrm{D}-a r g} / K_{\mathrm{m}}{ }^{\mathrm{D}-a r g}\right) /\left(k_{\mathrm{cat}}{ }^{\mathrm{L}-\text { arg }} / K_{\mathrm{m}}{ }^{\mathrm{L}-a r g}\right)$ for wild-type (0.362), G54S (0.235) and G54A (0.615) (see Table 1 and Fig. 3) shows that the G54A mutant enzyme was more specific towards D-arginine. These results suggest that even a residue remote from the guanidino substrate binding site, such as G54 in Sabellastarte AK2 (Fig. 1), can significantly affect guanidino substrate specificity.

Comparison of $K_{\mathrm{m}}{ }^{\mathrm{ATP}}$ values of wild-type and mutants of Sabellastarte $A K$

The wild-type enzyme of Sabellastarte AK2 showed the $K_{\mathrm{m}}{ }^{\text {ATP }}$ value of $1.13 \mathrm{mM}$ in 133 $\mathrm{mM}$ L-arginine, while it showed the value of $2.99 \mathrm{mM}$ in the same concentration of D-arginine (Table 3). Thus the enzyme shows 2.6-fold higher affinity for ATP in L-arginine than in D-arginine. In this condition, L- or D-arginine is nearly saturated in its substrate binding site of the enzyme. On the other hand, the $k_{\text {cat }}$ values are comparable (39.5 and $36.6 \mathrm{~s}^{-1}$, respectively) (Table 3 ).

Five mutants, G54S, G54A, L64I, L64V and Y89Q, showed higher affinity for ATP $\left(K_{\mathrm{m}}{ }^{\mathrm{ATP}}=0.400-0.930 \mathrm{mM}\right)$ than that $(1.13 \mathrm{mM})$ of wild-type in the L-arginine saturated condition (Table 3). In the D-arginine saturated condition, the affinities were also higher $\left(K_{\mathrm{m}}{ }^{\text {ATP }}=0.837-1.59 \mathrm{mM}\right)$ in the G54A, L64I and Y89Q mutants than that $(2.99 \mathrm{mM})$ of the wild-type, but lower $\left(K_{\mathrm{m}}{ }^{\mathrm{ATP}}=3.49-3.72 \mathrm{mM}\right)$ in G54S and L64V. The $k_{\text {cat }}$ values of the mutants were estimated to be $30 \%$ lower in the L-arginine saturated conditions. 
Thus it is suggested that slightly, but significant difference in the arrangement of the active center caused by the binding of L- or D-arginine, affected on the affinity of the other substrate ATP in Sabellastarte AK2 reaction.

\section{Conclusions}

Sabellastarte AK is the only phosphagen kinase using D-arginine as substrate. It is clearly unrelated to typical AK, and apparently evolved from a mitochondrial CK-like gene. In this study, we found several amino acid residues responsible for distinguishing the chiral substrates, D- and L-arginine. The 64th residue appears to be the most important determinant for recognizing the chirality of arginine, because the L64I and L64V mutations caused remarkable changes in substrate specificity for D- and L-arginine. Other residues, such as N320, Y89 and G54, also affect the guanidino substrate specificity of Sabellastarte AK2, but these residues might be involved simultaneously in other structural interactions that affect the stability of AK.

\section{Acknowledgements}

This work was supported by a Grant-in-Aid for Scientific Research in Japan to KU (21770080) and to TS (17570062 and 20570072).

\section{References}

[1] G.L. Kenyon, G.H. Reed, Adv Enzymol Relat Areas Mol. Biol. 54 (1983) 367-426.

[2] N.S. Lyzlova, E.V. Stefanov, Phosphagen Kinases, CRC Press, Boston, 1990.

[3] W.R. Ellington, Annu. Rev. Physiol. 63 (2001) 289-325.

[4] K. Uda, N. Saishoji, S. Ichinari, W.R. Ellington, T. Suzuki, FEBS J. 272 (2005) 3521-3530. 
[5] K. Uda, N. Fujimoto, Y. Akiyama, K. Mizuta, K. Tanaka, W.R. Ellington, T. Suzuki, Comp. Biochem. Physiol. D. 1 (2006) 209-218.

[6] M. Conejo, M. Bertin, S.A. Pomponi, W.R. Ellington, J. Mol. Evol. 66 (2008) $11-20$.

[7] L.D. Andrews, J. Graham, M.J. Snider, D. Fraga, Comp. Biochem. Physiol. B. 150 (2008) 312-319.

[8] K. Iwanami, S. Iseno, K. Uda, T. Suzuki, Gene. 437 (2009) 80-87.

[9] T. Suzuki, H. Fukuta, H. Nagato, M. Umekawa, J. Biol. Chem. 275 (2000) 23884-23890.

[10] T. Suzuki, M. Kamidochi, N. Inoue, H. Kawamichi, Y. Yazawa, T. Furukohri, W. Ellington, Biochem. J. 340 (1999) 671-675.

[11] K. Uda, T. Suzuki, Protein J. 26 (2007) 281-291.

[12] K. Tanaka, K. Uda, M. Shimada, K. Takahashi, S. Gamou, W.R. Ellington, T. Suzuki, J. Mol. Evol. 65 (2007) 616-625.

[13] T. Suzuki, Y. Kawasaki, T. Furukohri, W.R. Ellington, Biochim. Biophys. Acta. 1343 (1997) 152-159.

[14] S.D. Lahiri, P.F. Wang, P.C. Babbitt, M.J. McLeish, G.L. Kenyon, K.N. Allen, Biochemistry 41 (2002) 13861-13867.

[15] G. Zhou, T. Somasundaram, E. Blanc, G. Parthasarathy, W.R. Ellington, M.S. Chapman, Proc. Natl. Acad. Sci. USA. 95 (1998) 8449-8454.

[16] T. Suzuki, Y. Yamamoto, M. Umekawa, Biochem. J. 351 (2000) 579-585.

[17] J.F. Morrison, E. James, Biochem. J. 97 (1965) 37-52.

[18] N. Fujimoto, K. Tanaka, T. Suzuki, FEBS Lett. 579 (2005) 1688-1692.

[19] N. Guex, M.C. Peitsch, Electrophoresis. 18 (1997) 2714-2723.

[20] P.L. Edmiston, K.L. Schavolt, E.A. Kersteen, N.R. Moore, C.L. Borders, Biochim. Biophys. Acta. 1546 (2001) 291-298.

[21] K. Tanaka, T. Suzuki, FEBS Lett. 573 (2004) 78-82.

[22] T. Suzuki, K. Uda, M. Adachi, H. Sanada, K. Tanaka, C. Mizuta, K. Ishida, W.R. Comp. Biochem. Physiol. B. 152 (2009) 60-66.

[23] J.S. Cantwell, W.R. Novak, P.F. Wang, M.J. McLeish, G.L. Kenyon, P.C. Babbitt, Biochemistry. 40 (2001) 3056-3061.

[24] W. R. Ellington, T. Suzuki, in: C. Vial (Ed.), Creatine Kinase, NovaScience, New York, 2006, pp. 1-26.

[25] M.S. Yousef, S.A. Clark, P.K. Pruett, T. Somasundaram, W.R. Ellington, M.S. Chapman, Protein Sci. 12 (2003) 103-111.

[26] K. Uda, A. Kuwasaki, K. Shima, T. Matsumoto, T. Suzuki, Int. J. Biol. Macromol. 
44 (2009) 413-418. 


\section{Figure legends}

Figure 1: Three-dimensional structure of Sabellastarte AK2 docked to the substrates L-arginine (A) and D-arginine (B). The structure was generated by SWISS-MODEL and drawn with Swiss-PdbViewer [19].

Figure 2: Amino acid sequence alignment around the $\mathrm{N}$-terminal and $\mathrm{C}$-terminal flexible loop of Eisenia LK, Arenicola TK, Neanthes GK, Torpedo CK, Limulus AK and Sabellastarte AK1 and AK2. Sequence numbering is based on the Sabellastarte AK2 sequence. The amino acid residues mutated in this study are indicated by an asterisk (*).

Figure 3: Comparison of kinetic parameters for the wild-type and the Sabellastarte AK2 mutants. (A) The relative values of the catalytic efficiencies: $\left(k_{\mathrm{cat}} / K_{\mathrm{m}}\right.$ for D-Arg) $/$ $\left(k_{\text {cat }} / K_{\mathrm{m}}\right.$ for L-Arg), and (B) the relative values of the substrate affinities: $K_{\mathrm{m}}{ }^{\mathrm{D}-\mathrm{Arg}} / K_{\mathrm{m}}{ }^{\mathrm{L}-\mathrm{Arg}}$, for the wild-type and L64I, L64V, Y89Q, G54S and G54A mutants. (C) The relative values of the activities: D-Arg activity / L-Arg activity, for the wild-type and N320H, Q, D, E, R, $\mathrm{K}$ and A mutants. 

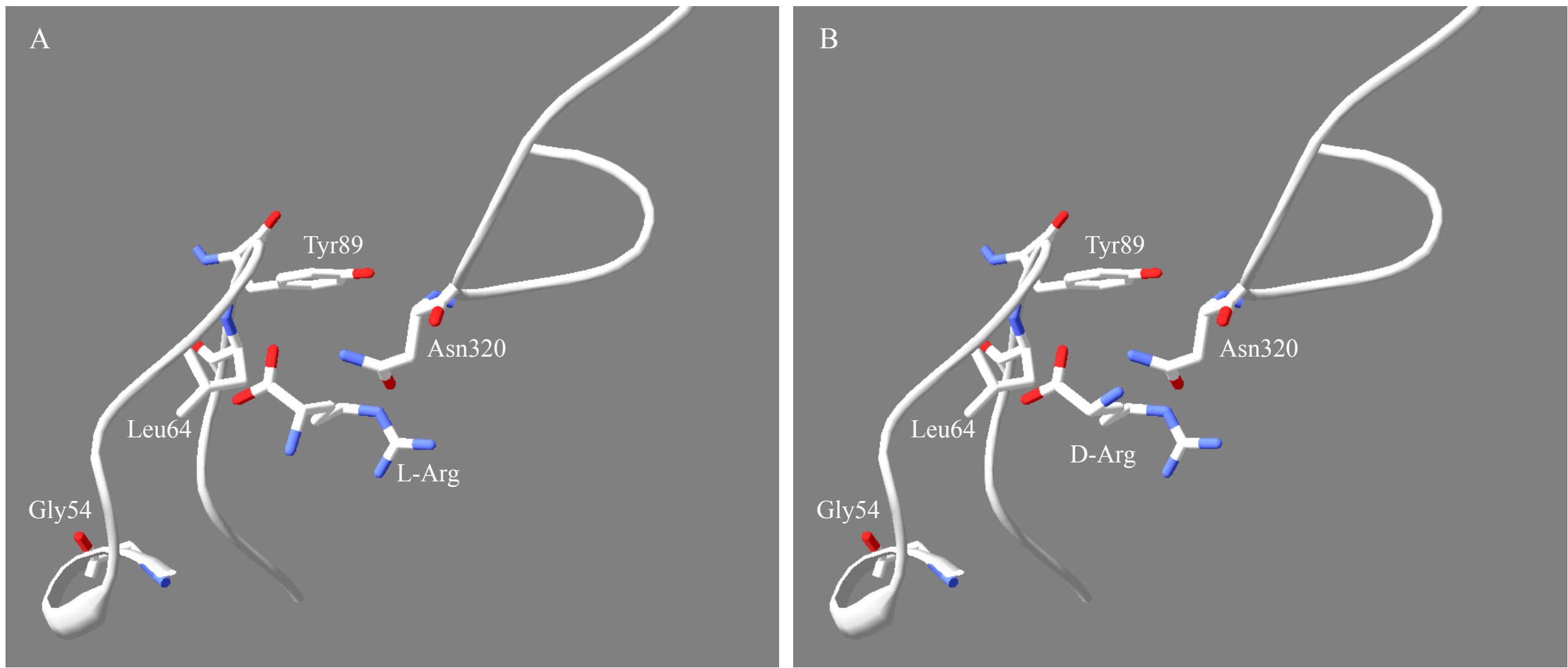
Eisenia LK Arenicola TK Neanthes GK Torpedo CK Limulus AK Sabellastarte AK1 Sabellastarte AK2 :CIQPSVDN-----TGRI IGLVAGDPESYEVFKELFDAVINEKHGGFGPTD :CIQPSVDY-----TGKIVGLVAGDEESYTTFNEIFDAVLDDHHLGFSTTD :CIQTGVDNPGNKFYGKKTGCVFGDEHSYETFKDFFDRCIEEIHH-FKPTD : IIQTGVDNPGHP-FIMTVGCVAGDEECYEVFKDLFDPVIEDRHGGYKPTD :VIQSGVEN-----LDSGVGIYAPDAESYRTFGPLFDP I IDDYHGGFKLTD :CIQPACEYVR---DEKI IGLVAGDEHSFEVFKDLFDPVINEQHSGFGPSE : CIQIGCEQPKP--DEKLIGLVAGDEYCYDVFSELFDPVINEYHMGFGPEE
C-terminal flexible loop GTGGEHTEAVDDV GTAGEHTAAVDDV GTGGESSLAEDST GTGGVDTAAVGSI GTRGEHTESEGGV GTGGENSATVDDT GTGGENTETVDFT 


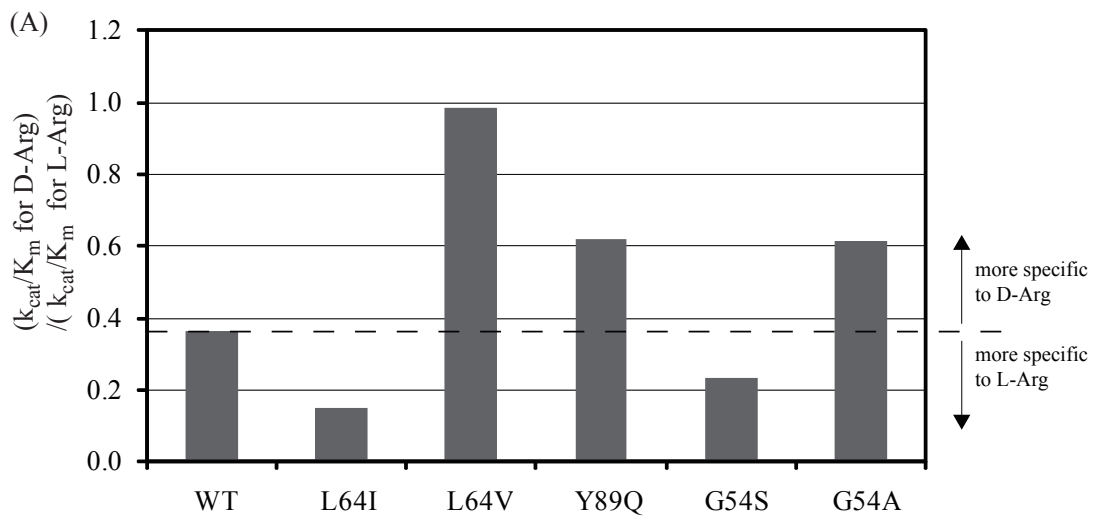

(B)
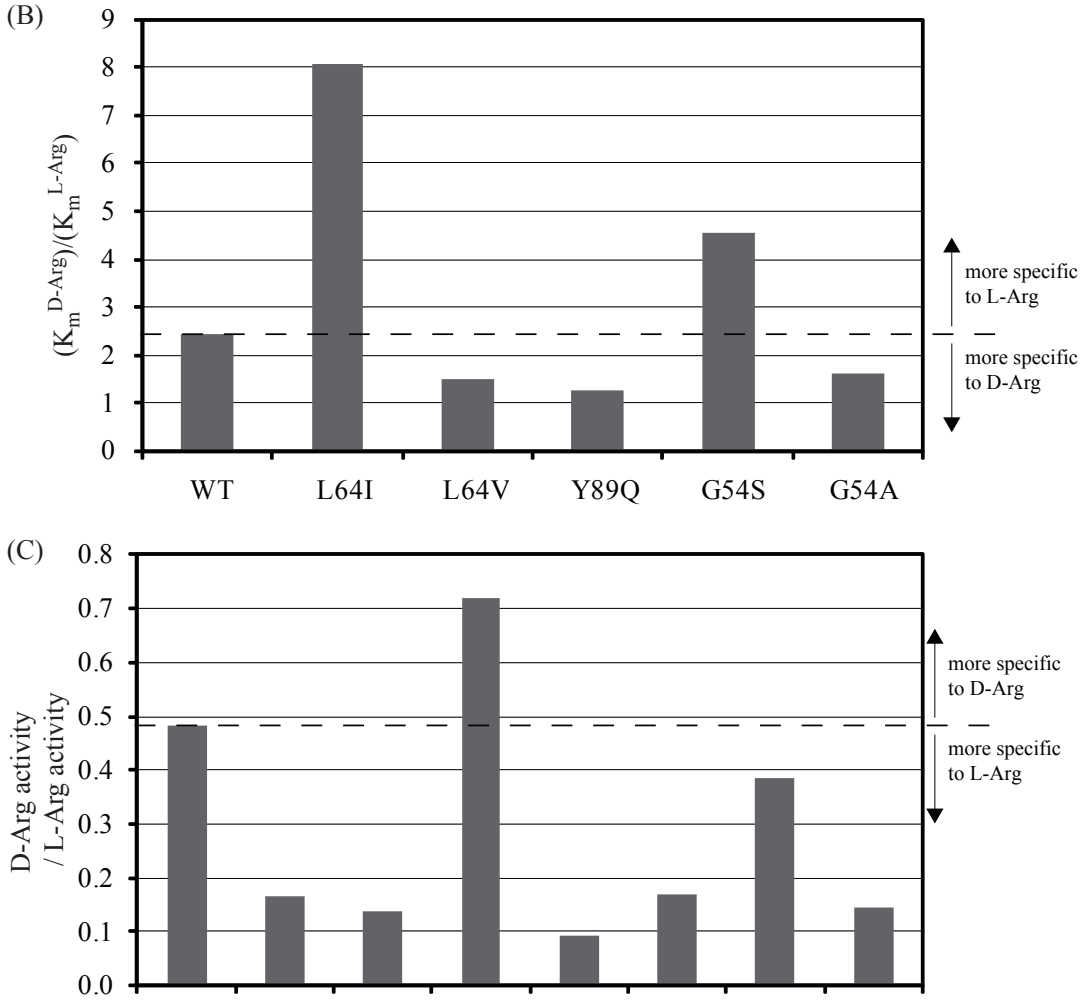
Table 1 Kinetic parameters for the forward reaction of the wild-type and mutants of Sabellastarte AK2.

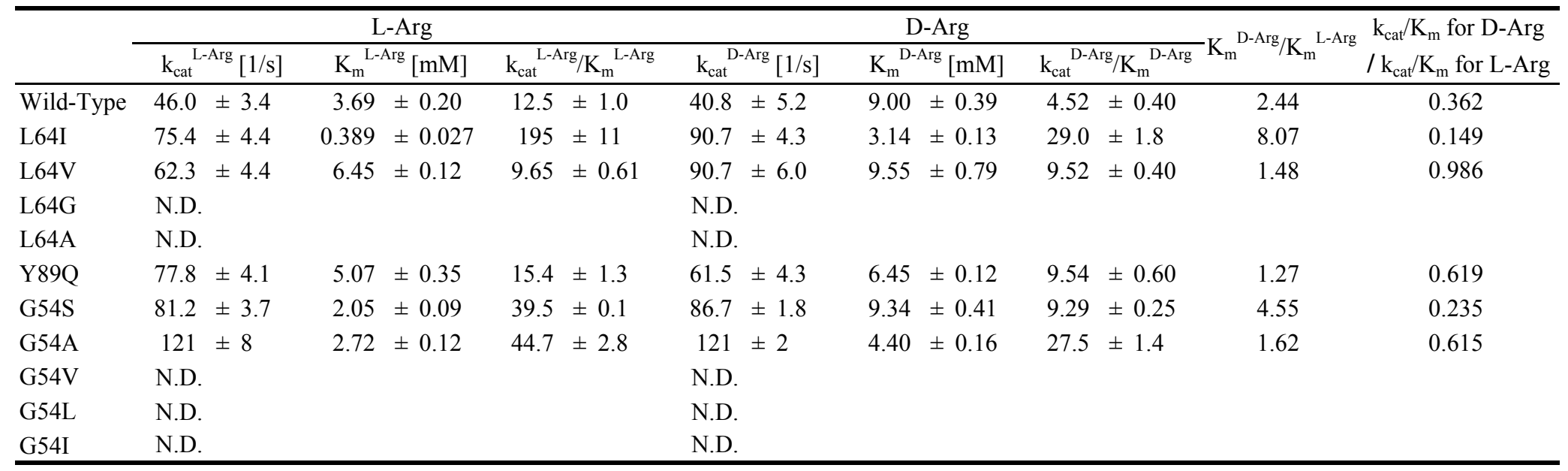


Table 2 Enzyme activity of the wild-type and Asn320 mutants of Sabellastarte AK2.

\begin{tabular}{|c|c|c|c|c|c|c|c|}
\hline \multirow[b]{3}{*}{ wt } & \multicolumn{6}{|c|}{ Enzyme activity [ $\mu$ moles $\min ^{-1} \mathrm{mg}$ protein $\left.{ }^{-1}\right]$} & \multirow{3}{*}{$\begin{array}{l}\begin{array}{l}\text { D-Arg activity } \\
\text { / L-Arg activity }\end{array} \\
0.483\end{array}$} \\
\hline & \multicolumn{3}{|c|}{ L-Arg } & \multicolumn{3}{|c|}{ D-Arg } & \\
\hline & 30.8 & \pm 1.2 & (100) & 14.9 & \pm 0.3 & $(100)$ & \\
\hline N320H & 9.08 & \pm 0.26 & $(29.5)$ & 1.51 & \pm 0.15 & $(10.2)$ & 0.166 \\
\hline N320Q & 2.77 & \pm 0.05 & $(8.97)$ & 0.386 & \pm 0.030 & $(2.60)$ & 0.139 \\
\hline N320D & 10.0 & \pm 0.2 & $(32.4)$ & 7.20 & \pm 0.50 & $(48.4)$ & 0.719 \\
\hline N320E & 16.1 & \pm 0.4 & $(52.3)$ & 1.50 & \pm 0.42 & $(10.1)$ & 0.093 \\
\hline N320R & 1.27 & \pm 0.18 & $(4.11)$ & 0.216 & \pm 0.029 & $(1.46)$ & 0.171 \\
\hline N320K & 0.189 & \pm 0.011 & $(0.612)$ & 0.0726 & \pm 0.0066 & $(0.489)$ & 0.385 \\
\hline N320A & 5.27 & \pm 0.34 & $(17.1)$ & 0.771 & \pm 0.081 & $(5.19)$ & 0.146 \\
\hline
\end{tabular}

The reaction was measured in the concentration of $4.76 \mathrm{mM}$ each of creatine and ATP at $25^{\circ} \mathrm{C}$. Values in parentheses are the relative value (\%) to its wild-type. 
Table $3 \mathrm{~K}_{\mathrm{m}}{ }^{\mathrm{ATP}}$ and $\mathrm{k}_{\mathrm{cat}}$ of the wild-type and mutants of Sabellastarte AK2. Kinetic parameters were obtained in $133 \mathrm{mM} \mathrm{L}$ - or D-arginine.

\begin{tabular}{lccccrr}
\hline & \multicolumn{2}{c}{ L-phosphoarginine synthesis } & \multicolumn{3}{c}{ D-phosphoarginine synthesis } \\
\cline { 2 - 7 } & $\mathrm{k}_{\text {cat }}{ }^{\text {ATP }}[1 / \mathrm{s}]$ & $\mathrm{K}_{\mathrm{m}}{ }^{\text {ATP }}[\mathrm{mM}]$ & $\mathrm{k}_{\mathrm{cat}}{ }^{\text {ATP }}[1 / \mathrm{s}]$ & $\mathrm{K}_{\mathrm{m}}{ }^{\text {ATP }}[\mathrm{mM}]$ \\
\hline Wild-Type & $39.5 \pm 1.9$ & $1.13 \pm 0.14$ & $36.6 \pm 2.6$ & 2.99 & \pm 0.40 \\
L64I & $50.1 \pm 0.7$ & $0.400 \pm 0.021$ & $68.3 \pm 3.3$ & $0.837 \pm 0.077$ \\
L64V & $43.3 \pm 1.3$ & $0.774 \pm 0.038$ & $61.8 \pm 5.6$ & $3.72 \pm 0.52$ \\
Y89Q & $33.4 \pm 2.2$ & $0.930 \pm 0.080$ & $41.9 \pm 4.7$ & $1.59 \pm 0.34$ \\
G54S & $43.2 \pm 0.6$ & $0.926 \pm 0.033$ & $60.7 \pm 3.9$ & $3.49 \pm 0.36$ \\
G54A & $41.0 \pm 1.3$ & $0.661 \pm 0.077$ & $65.8 \pm 1.3$ & $1.12 \pm 0.13$ \\
\hline
\end{tabular}




\section{Supplementary Material:}

sTable 1. Primers used for site-directed mutagenesis of Sabellastarte AK2.

\begin{tabular}{|c|c|c|}
\hline Mutation & Primer name & Sequence \\
\hline \multirow[t]{2}{*}{ G54S } & SabAK2.m67F & CTTGTGAACAGCCTAAGCCAGATG \\
\hline & SabAK2.m83R & AAATTTGTATGCACTTGTCTAGAG \\
\hline \multirow[t]{2}{*}{ G54A } & SabAK2.m67F & CTTGTGAACAGCCTAAGCCAGATG \\
\hline & SabAK2.m67R & CAATTTGTATGCACTTGTCTAGAG \\
\hline \multirow[t]{2}{*}{ G54V } & SabAK2.F54-Ntg & TGTGTGAACAGCCTAAGCCAGATG \\
\hline & SabAK2.m67R-R54-gNN & CAATTTGTATGCACTTGTCTAGAG \\
\hline \multirow[t]{2}{*}{ G54L } & SabAK2.F54-Ntg & TGTGTGAACAGCCTAAGCCAGATG \\
\hline & SabAK2.R54-cNN & GAATTTGTATGCACTTGTCTAGAG \\
\hline \multirow[t]{2}{*}{ G54I } & SabAK2.F54-Ntt & TTTGTGAACAGCCTAAGCCAGATG \\
\hline & SabAK2.R54-aNN & TAATTTGTATGCACTTGTCTAGAG \\
\hline \multirow[t]{2}{*}{ L64I } & SabAK2m1F & ATCATTGGTTTGGTTGCAAATGACG \\
\hline & SabAK2m1R & TTTCTCATCTGGCTTAGGCTGTTC \\
\hline \multirow[t]{2}{*}{ L64V } & SabAK2.m15F & GTCATTGGTTTGGTTGCAGGTGACG \\
\hline & SabAK2.m08R & TTTCTCATCTGGCTTAGGCTGTTC \\
\hline \multirow[t]{2}{*}{ L64G } & SabAK2.m41F & GGCATTGGTTTGGTTGCAGGTGACG \\
\hline & SabAK2.m08R & TTTCTCATCTGGCTTAGGCTGTTC \\
\hline \multirow[t]{2}{*}{ L64A } & SabAK2.m16F & GCCATTGGTTTGGTTGCAGGTGACG \\
\hline & SabAK2.m08R & TTTCTCATCTGGCTTAGGCTGTTC \\
\hline \multirow[t]{2}{*}{ Y89Q } & SabAK2m2F & AACATATGGGATTTGGTCCAGAAG \\
\hline & SabAK2m2R & GTTCATTAATCACTGGGTCAAAAG \\
\hline \multirow[t]{2}{*}{ N320H } & SabAK2.m12F & CACACTGAGACTGTAGATTTTACC \\
\hline & SabAK2.m12R & TTCTCCACCCGTTCСССТCTTG \\
\hline \multirow[t]{2}{*}{ N320Q } & SabAK2.m23F & CAGACTGAGACTGTAGATTTTACC \\
\hline & SabAK2.m12R & TTCTCCACCCGTTCCССТCTTG \\
\hline \multirow[t]{2}{*}{ N320D } & SabAK2.m24F & GACACTGAGACTGTAGATTTTACC \\
\hline & SabAK2.m12R & TTCTCCACCCGTTCСССТCTTG \\
\hline \multirow[t]{2}{*}{ N320E } & SabAK2.m30F & GAGACTGAGACTGTAGATTTTACC \\
\hline & SabAK2.m12R & TTCTCCACCCGTTCСССТCTTG \\
\hline \multirow[t]{2}{*}{ N320R } & SabAK2.m29F & CGCACTGAGACTGTAGATTTTACC \\
\hline & SabAK2.m12R & TTCTCCACCCGTTCСССТCTTG \\
\hline \multirow[t]{2}{*}{ N320K } & SabAK2.m31F & AAGACTGAGACTGTAGATTTTACC \\
\hline & SabAK2.m12R & TTCTCCACCCGTTCCССTCTTG \\
\hline \multirow[t]{2}{*}{ N320A } & SabAK2.m64F & CGACTGTAGATTTTACCTATGACATC \\
\hline & SabAK2.m64R & CAGTGTTTTCTCCACCCGTTCCCC \\
\hline
\end{tabular}

